\title{
Aluminium depletion in NiCrAlY bond coatings by hot corrosion as a function of projection system.
}

\author{
M.C. Mayoral ${ }^{1}$, J.M. Andrés ${ }^{1}$, M.T. Bona ${ }^{1}$, V. Higuera ${ }^{2}$, F.J. Belzunce ${ }^{3}$ \\ 1: Instituto de Carboquímica, CSIC. C/Miguel Luesma, 4. 50018 Zaragoza (Spain) \\ 2: Mechanical Engineering Dep., University of Oviedo, 33203 Gijón (Spain) \\ 3: Materials Science Dep., University of Oviedo, 33203 Gijón (Spain)
}

\begin{abstract}
Three different projection system are used to prepare NiCrAlY bond coats over metallic substrates: atmospheric plasma spray (APS), high velocity oxyfuel (HVOF) and high frequency pulse detonation (HFPD). These coatings were tested in hot corrosion experiments with sprayed $\mathrm{Na}_{2} \mathrm{SO}_{4}$ at $1000^{\circ} \mathrm{C}$ for 20 and 100 hours experiments in air. Coatings surface composition after thermal treatment was characterised by XRD and SEM. Cross section of coatings were analysed by SEM-EDX. A relationship between microstructural characteristics of initial coatings and final performance in hot corrosion was found in terms of porosity percentage: plasma sprayed coatings present higher percentage of porosity compared to HVOF and HFPD projection systems for the same composition and $\mathrm{Al}$ is heavily consumed in interparticle oxidation. This Al depletion in turn involves intrinsic chemical failure and surface layer is comprised by a porous spinel of mixed oxides. On the other hand, high energy projection systems produce dense coatings allowing the Al migration to external alumina layer, particularly in the case of HVOF coating.
\end{abstract}

Keywors: NiCrAlY bond coats, Hot corrosion, Al depletion, HVOF, HFPD

\section{INTRODUCTION}

The degradation during service of turbine blades thermal insulation is one of the major concern in material science research in the field of energy production. It is well established that the durability of the ceramic top coat in thermal barrier coatings (TBC) is related to the physical and chemical changes of metallic bond coat due to oxidation: an interface layer of thermally grown oxide is the final responsible of top coat adherence, and its thermal coefficient of expansion and physical stress determine the incidence of cracking and spallation $[1,2]$. There are a number of existing methods to prepare protective coatings onto superalloys, falling into two main categories: diffusion coatings (by pack cementation, electrodeposition, vapor deposition, ...) $[3,4]$ and overlay coatings, deposited by thermal spray methods, with a common composition of $\mathrm{MCrAlX}$, where $\mathrm{M}$ is $\mathrm{Ni}$, Co or their combinations, and $\mathrm{X}$ a reactive element such us $\mathrm{Y}, \mathrm{Ce}, \mathrm{Hf}, \mathrm{Zr}$ or Si with high affinity with oxygen. The behaviour against isothermal 
and cyclic oxidation for different MCrAlX types has been deeply studied as a function of element composition and service conditions. Those kinetic and morphologic studies have demonstrated that a uniform and continuous layer of surface generated $\mathrm{Al}_{2} \mathrm{O}_{3}$ involves high degree of protection against alloy oxidation, provided that enough $\mathrm{Al}$ is present in the bond coat, which behaves as a $\mathrm{Al}$ reservoir $[5,6]$. The formation of non protective oxide such as $\mathrm{NiO}$ and spinel $\mathrm{NiAl}_{2} \mathrm{O}_{4}$, either between the TGO and the bond coat or between the TGO and the TBC during oxidation, has been identified as a source of brittleness that may result in delamination $[7,8]$. In fact, surface and grain structure imperfections promote failure through their influence on the TGO instability sites [9].

The most common deposition technique is plasma spraying (PS). In a plasma spraying gun, a high current arc is generated within a torch and a gas is heated and converted into a high temperature $(10,000 \mathrm{~K}$ have been measured in some cases), where powdered surfacing material is injected and accelerated $\left(600 \mathrm{~m} \cdot \mathrm{s}^{-1}\right)$ onto the substrate in molten state. In this way a dense coating with small splat size and high bonding strength is generated. Nevertheless, the high temperatures attained during projection deal to certain degree of particle oxidation, and vacuum and low pressure plasma spraying (VPS or LPPS) have been designed to enhance coating quality. Recent developments in spray guns producing supersonic flame speeds, with maximum temperature around 2700-3200K, decrease the chances for metallic particles to oxidise along the combustion flame, rendering in a more dense and less oxidised coating. This technique is called High velocity oxyfuel (HVOF), and comparison of PS and HVOF coatings can be found in terms of microstructure, adhesion and oxidation resistance improvements [10-12].

In general, it is commonly accepted that HVOF produces a more dense and less oxidised coating $[13,14]$. More recently, the new High Frequency Pulse Detonation (HFPD) spray process represents a cost effective alternative for the production of premium quality coatings $[15,16]$. The HFPD spray system is based on a carefully designed gun able to produce discontinuous behaviour (cycled explosions, up to $>100 \mathrm{~Hz}$ ) from a continuous supply of detonable gases and sprayed powders. In the HFPD process, the flow of gaseous products from cycled explosions in the gun is used to accelerate and heat the sprayed particles. Typically, these particles attain very high speeds and sufficiently high temperatures, leading to a quite dense, well bonded coatings from most commercially available powders. One of the most important consequences of the particular physical process involved in HFPD cycled explosions is the low consumption of gases, mainly when compared with alternative continuous HVOF systems. This is due to two factors: the different oxyfuel ratios (low oxygen) and the pulsed nature of the process. Another important economic consideration is its extended operating time and low maintenance requirements $[16,17]$. Comparison of the three projection methods, plasma, HVOF and HFPD can be found in terms of substrate-coating adherence and microhardness. It was found that HVFO and HFPD coatings had similar high values of adherence (ASTM C633 standard) both in the as-sprayed samples and after thermal fatigue conditions, in respect to plasma sprayed coatings. The results indicated a clear 
relationship between the oxide content in the coating, calculated as average percentage in volume determined by means of optical microscopy techniques [18,19]. The present work is as well a comparison of the three spraying procedures of a NiCrAlY coating in terms of resistance to accelerated oxidation in the presence of $\mathrm{NaCl}$ and $\mathrm{Na}_{2} \mathrm{SO}_{4}$ salts in an oxidizing atmosphere at elevated temperatures. This mode of attack is called 'hot corrosion', and, unlike oxidation, the outer oxide material in blade surfaces is consumed at an unpredictable rapid rate. The origin of $\mathrm{NaCl}$ in the turbine combustion chamber is from air impurities, which, combined with gaseous sulphur oxides from fuel impurities, react into sodium sulphate aerosols that impact and condense onto turbine blade surfaces. According to the proposed chemical mechanism for hot corrosion [20], protection efficiency of the thermally grown surface oxide layer might be lost as a result of fluxing of this layer in the molten salt. High temperature hot corrosion behaviour of superalloys, intermetallics and coatings is normally studied as the effect of accelerated oxidation in the presence of $\mathrm{Na}_{2} \mathrm{SO}_{4}$ salts by means of X-ray diffraction characterization of degraded surfaces and cross-section morphologies by Scanning electron microscopy [21-24]. Several examples of comparative studies of corrosion resistance to accelerated corrosion by $\mathrm{Na}_{2} \mathrm{SO}_{4}$ can be found for different coating composition for the same projection procedure [25]. The influence of the spraying processes (plasma and HVOF) has been studied in terms of corrosion in polarisation measurements [26] and in hot corrosion environments [27]. It is commonly accepted that HVOF dense coating resulted to be more resistant to hot corrosion [28] but this is the first work in which resistance to hot corrosion of a NiCrAlY coating is compared in terms of projection system including plasma spraying, HVOF and HFPD.

\section{EXPERIMENTAL PROCEDURE.}

The coating materials were commercial NiCrAlY powders $(67.10 \% \mathrm{wt} \mathrm{Ni}, 21.89 \%$ wt $\mathrm{Cr}, 10.01 \% \mathrm{wt} \mathrm{Al}$ and $0.99 \%$ wt $\mathrm{Y}$ ) of two different granulometries which were sprayed onto substrates of grit blasted AISI 310 stainless steel by means of the three thermal spray methods: atmospheric plasma (APS) with a Metco plasma gun, high velocity oxyfuel (HVOF) with a Metco HDJ gun and high frequency pulse detonation (HFPD) with a PK HFPD thermal spray apparatus (Aerostar Coatings). The most relevant spraying parameters are listed in Table 1.

The porosity and oxide content of the coatings were evaluated by point counting under an optical microscope, in accordance with ASTM standard E-562. Vickers microhardness tests were also performed on the coating layers, using a load of $200 \mathrm{~g}$. Those parameters are described in Table 2. The porosity differences between plasma and high energy procedures (HVOF and HFPD) may be highlighted.

The samples were cut in squares of $5 \mathrm{~mm}$ side and a saturated dissolution of $\mathrm{Na}_{2} \mathrm{SO}_{4}$ was sprayed onto them by an aerograpgh airbrush to produce a salt film of $2.5 \mathrm{mg} . \mathrm{cm}^{-2}$. The coupons were then placed in 
a an alumina boat for thermal treatment. High temperature hot corrosion test were carried out in air, using a laboratory muffle furnace maintained at $1000^{\circ} \mathrm{C}$ for the desired period (20 or 120 hours). The same thermal treatment were performed onto bare samples as reference.

The phase composition of the coatings surface was determined by X-ray diffraction analysis using a Bruker D8 device. The microstructure of the samples has been studied by means of scanning electron microscopy in a Hitachi S-3400 N microscope equipped with a Si(Li) EDX detector Röntec XFlash, both in surface analysis as in cross-section polished samples.

\section{RESULTS.}

\subsection{Surface characterization.}

Surface morphology in SEM (secondary electrons) presented by the APS and HFPD coatings after 120 hours oxidation at $1000^{\circ} \mathrm{C}$ is shown in Figure 1: the outer surface is composed of smooth grains outlined by ridges, typical of an outward growing coating, with the characteristic $\alpha-\mathrm{Al}_{2} \mathrm{O}_{3}$ formations, with the absence of acicular metaestable of $\theta-\mathrm{Al}_{2} \mathrm{O}_{3}$ whiskers. The thermally grown oxide seems uniform.

Figure 2. shows the external morphology of coatings once thermally treated with the $\mathrm{Na}_{2} \mathrm{SO}_{4}$ film. The surface roughness has increased with salt treatment and time for the three coatings, with the appearance of alloying element precipitates and fine grains more or less detached from the surface.

$\mathrm{X}$-Ray characterization of these surfaces is shown in Figure 3. It is clearly seen in the range of 35 to 40 $2 \theta$ that thermal treatment without salt has developed an outer oxide surface comprised of alumina and spinels of mixed $\mathrm{Al}$ and $\mathrm{Ni}$ oxides. For each coating, the spinel peak increases when the coating has been covered with $\mathrm{Na}_{2} \mathrm{SO}_{4}$ salt, these results are in agreement with SEM morphology.

The X-ray crosses this outer oxide surface and characterizes the metallic NiAl substrate, identified as $\mathrm{Ni}_{3} \mathrm{Al}$ structure, as it can be seen in the main peaks at 44 and $512 \theta$ for all cases except for the R120 sample, where the main peak does not correspond to $\mathrm{Ni}_{3} \mathrm{Al}$. A magnification of the diffractogram in the 40-47 $2 \theta$ section is shown in Figure 4. In the case of R120, the JCP data base identifies the main metallic substrate as $\mathrm{Ni}$, and a small peak of $\mathrm{Ni}$ oxide is clearly seen. The displacement of main peak from $\mathrm{Ni}_{3} \mathrm{Al}$ to $\mathrm{Ni}$ indicates the lack of detection of metallic $\mathrm{Al}$ in the surface.

\subsection{Cross section characterization.}

Polished samples of cross sections of coupons were analyzed by SEM. Backscattered electrons micrographs are displayed in Figure 5. for the blank and salt coated coupons. In the figure, it is possible to see how a 120 hours thermal treatment produces a dense and continuous alumina surface layer for the three coatings (dark oxides in pictures bR120, bS120 and bT120). Initial grain structure seems unaltered: while APS coating shows the abundant porosity, HVOF and HFPD coatings seem dense and well melted. 
When the salt sprayed R coupon is thermally treated for 20 hours (micrograph R20 in Figure 5), an oxide layer has grown in the surface, but also intergranular oxidation appears as a layer of dark oxides around grains, identified as Al oxide. Longer oxidation times (micrograph R120 in Figure 5) produces a catastrophic evolution of oxidation: on one hand, outer layer is thinner than that showed by R20, which indicates a destruction of the thermally grown protective outer oxide. On the other hand, the intergranular oxidation has reached such a degree that the intergranular oxides are not only alumina (dark oxides) but also $\mathrm{Cr}$ and $\mathrm{Ni}$ oxides (lighter oxides around grains). Metallic grains are enriched in Ni whereas $\mathrm{Cr}$ appears in darker areas inside grains.

Coating S after hot corrosion attack (samples S20 and S120) shows a continuous outer surface layer and an unaltered intergranular structure as compared to blank test (S120b).

On the contrary, salt sprayed coating T treated for 20 and 120 hours (T20 and T120) shows a certain increase in intergranular oxidation and a change in continuity and composition of the thermally grown oxide, with the appearance of lighter oxides identified by EDX as spinels.

Higher magnifications in SEM micrographs are shown in Figure 6 for coating R, with Al percentage of selected points determined by EDX. TGO for bR120 sample is composed of alumina, with an outer porous layer of mixed oxides of alumina and chromium. Holes in the metallic matrix indicate the mass migration to form the TGO. In the case of the coating R covered with salt (R120), the thermal treatment has developed a thin and porous external oxide layer composed of mixed oxides of $\mathrm{Al}, \mathrm{Cr}$ and $\mathrm{Ni}$, over a thinner layer of alumina. EDX analysis of selected points in the metallic matrix denotes the absence of $\mathrm{Al}$ in the coating: aluminium has migrated to the outer surface to form the oxide layer and, simultaneously, to form a interparticle alumina layer. The metallic coating has been completely depleted in $\mathrm{Al}$, as it was denoted by the XRD difractogram in Figure 3. On the other hand, XRD detected the presence of $\mathrm{NiO}$ in the outer surface (Figure 4) although EDX of the polished cross sections cannot assign single nickel oxide presence.

SEM micrographs and composition by EDX for coatings S and T for both blank and salt coated samples, are shown in Figures 7 and 8 respectively. In both cases, the blank experiments have produced a dense an homogenous alumina layer (bS120 and bT120) with an external presence of mixed oxides and spinels. The salt sprayed coupons have developed as well a dense layer of alumina, slightly thinner than in the blank experiments, with an outer discontinuous layer of spinel with the same composition than that presented over the TGO in blank tests. This mixed oxide external layer seems to be thicker in the case of T120 than for S120, which agrees with XRD composition in Figure 3. It is worth mentioning that Y oxide appears as isolated lighter grains as it can be seen in Figure 6 and Figure 7.

The internal presence of $\mathrm{Al}$ is quantified by $\mathrm{EDX}(\mathrm{Al}+\mathrm{Cr}+\mathrm{Ni}$ normalised to 100 in weight $)$ for coating $\mathrm{S}$ in several points at 10 microns depth. As it can be seen in Figure 7, dark points of internal oxidation are richer in $\mathrm{Al}$ than the metallic matrix, which is around a 5\%wt for both the blank and the salt treated coupons. The results obtained with the blank T coupon (bS120) are similar (Figure 8), although T120 


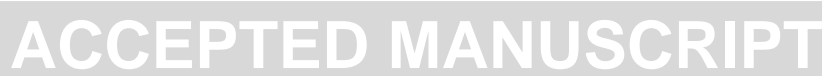

present slightly lower Al\%wt, around a 4.2\%. Provided that this difference is inside the analytical error expected for $\mathrm{Al}$ quantification $( \pm 1 \%)$, these results cannot be assigned to $\mathrm{Al}$ depletion in metallic matrix. To minimise both analytical uncertainty and matrix heterogeneity effect, a study of EDX results of single spots and square areas was performed (Figure 9) over a cross section of coupon bS120. In the picture it is possible to see that both squares 1 and 2 have a similar Al presence of a $11 \%$, whereas those spots selected in the matrix have $6 \% \mathrm{Al}$ and points impacting on alumina grains are $40 \% \mathrm{Al}$. In this way, EDX microanalysis of $25 \mu \mathrm{m}$ side squares was used to compare coupons composition along thickness. Figure 10 is the comparison of $\mathrm{Al}$ presence $(\mathrm{Al}+\mathrm{Cr}+\mathrm{Ni}$ normalised to 100 in weight $)$ in selected square areas for samples bS120, S120, bT120 and T120. This analysis cannot find a variation in Al presence for coating S, while EDX indicates a meaningful depletion of $\mathrm{Al}$ from $9 \%$ to $6.5 \% \mathrm{wt}$ in coating $\mathrm{T}$ when it is thermally treated after salt deposition.

\section{DISCUSSION}

\subsection{Coatings surface accelerated oxidation.}

It has been described in the Results section that the three coatings studied developed a dense and homogeneous $\alpha$-alumina layer along thermal treatment at $1000^{\circ} \mathrm{C}$ for 120 hours, with a thin spinel layer remaining at the surface. This is in fact the expected behaviour of overlay Ni-Al coatings [29], where oxidation is intended to occur on the outer surface as protective barrier against oxidation progression. The kinetic parameters related to TGO formation has been deeply studied in static and cyclic conditions [19], and the mechanism of protection failure due degradation has been described as a sequence of the following steps: rumpling of the surface, formation of cracks and oxide scale spallation for long periods of heavy duty turbine blades. The situation described in this work is different, it consists of the accelerated oxidation, named as hot corrosion, produced by the fused $\mathrm{Na}_{2} \mathrm{SO}_{4}$ salt deposited onto coatings surfaces. The different surface morphology is clearly seen in Figure 2, when thermal treatment is applied to salt-coated samples, and cross section micrograph of the coatings in Figure 5 demonstrates that the presence of fused salt has hindered the formation of the protective TGO for coating R.

There are two proposed mechanisms of high temperature high corrosion due to molten sulphates. In one hand, the oxide-sulphide formation mechanism precludes that the consumption of oxygen in the molten salt for oxides formation locally reduces the partial pressure oxygen, increasing Pp of sulphur according to reaction [1], with the formation of sulphides in the salt/alloy interface:

$\mathrm{Ni}+\mathrm{Na}_{2} \mathrm{SO}_{4} \rightarrow \quad \mathrm{NiO}_{\mathrm{x}} \cdot \mathrm{Na}_{2} \mathrm{O}+\mathrm{SO}_{3}$

Since the produced sulphide is thermodynamically unstable when the partial pressure of oxygen increases, it is possible for sulphide to convert into outer oxides $\left(\mathrm{NiO}, \mathrm{Al}_{2} \mathrm{O}_{3}, \mathrm{NiAl}_{2} \mathrm{O}_{4}\right)$ [30]. 
On the other hand, the formation of the spinel phase could be explained as well through the dissolution of $\mathrm{Al}$ and $\mathrm{Ni}$ by the molten salt, developing into the generation of porous mixed oxides after the equation [2], which is named the dissolution-oxidation fluxing mechanism:

$\mathrm{Al}_{2} \mathrm{O}_{3}+\mathrm{O}^{2-}=2 \mathrm{AlO}^{2-} \quad\left(\right.$ spinels such as $\mathrm{NiAl}_{2} \mathrm{O}_{4}$ )

The absence of $\mathrm{Ni}$ and $\mathrm{Cr}$ sulphides in the EDX analysis underneath the TGO and the increase in spinel thickness (Figures 6) and peak intensities in XRD (Figure 3) in salt sprayed R coating compared to blank one seem to indicate that this fluxing mechanism is the responsible of the lack of formation of the protective alumina layer and the formation of the porous spinel. In this way, penetration of molecular oxygen along splat boundaries is allowed in the plasma sprayed coating, with the individual particles surrounded by a dense, adherent and continuous alumina layer. These catastrophic internal oxidation involves the reduction of residual aluminium concentration within the splat particle, with the complete depletion of $\mathrm{Al}$ as it was pointed out by SEM and XRD analysis. In fact, the transformation of $\gamma^{\prime}-\mathrm{Ni}_{3} \mathrm{Al}$ to $\mathrm{Ni}$, detected by XRD, involves a theoretical volume contraction of $29 \%\left(\operatorname{density}\left(\gamma^{\prime}-\mathrm{Ni}_{3} \mathrm{Al}\right)=7.5 \mathrm{gr}^{-\mathrm{m}^{-3}}\right.$ and density $(\mathrm{Ni})=8.9 \mathrm{gr} . \mathrm{cm}^{-3}$ ). The presence of these voidlike defects lying adjacent to spinels can easily initiate the oxide spallation.

Moreover, the presence of intrinsic chemical failure (Incf) is detected: the supply of Al has become insufficient to match the incoming oxygen flux and oxides otherwise not expected to be found, are present in the surface, as $\mathrm{NiO}$ detected by XRD in Figure 4.

The conjunction of these multiple mechanism of oxidation-fluxing-depletion was explored with two new experiments. Projection powders of the two granulometries studied ( $\mathrm{pR}=38-75 \mu \mathrm{m}$ and $\mathrm{pT}=10-45 \mu \mathrm{m})$ were preoxidised in a muffle furnace for 20 hours at $1000^{\circ} \mathrm{C}$ and $\mathrm{XRD}$ analysis confirmed the formation of external alumina (pRpox and pTpox lines in Figures 11. and 12.). Afterwards, these preoxidised powders were manually mixed with $\mathrm{Na}_{2} \mathrm{SO}_{4}$ grains in an agate mortar and again treated in a muffle furnace for 2 hours at $1000^{\circ} \mathrm{C}$ (samples RS and TS). The difractograms confirmed the formation of spinel, the depletion of aluminium and the intrinsic chemical failure with the formation of chromium oxide for the thicker powders, and alumina absence, $\mathrm{Al}$ depletion and $\mathrm{Cr}_{2} \mathrm{O}_{3}$ and $\mathrm{NiO}$ formation for the thinner powders, were the supply of Al to the oxide-metal interface becomes fast insufficient to match the incoming oxygen flux.

\subsection{Comparison of projection system.}

The oxidation-dissolution fluxing mechanism that explains surface spinel formation and thinner TGO in salt-coated samples is related to chemical composition of the metallic matrix, which is the same in the case of the three coatings studied in this work. Nevertheless, coating $\mathrm{R}$ is affected by intrinsic chemical failure in salt sprayed experiments in a higher extent than coatings $\mathrm{S}$ and $\mathrm{T}$ are, with a complete $\mathrm{Al}$ depletion at $10 \mu \mathrm{m}$ depth, so mixed $\mathrm{Ni}$ and $\mathrm{Cr}$ mixed porous oxides grow in the surface. The main 
difference of coating $\mathrm{R}$ with coatings $\mathrm{S}$ and $\mathrm{T}$ is the formation of interparticle alumina. This oxidation is only possible due to coating porosity: oxygen can reach interparticle surfaces through the $15 \%$ volume void calculated for surface section (Table 2). The main consequence of aluminium consumption is the final hindrance to formation of a protective alumina oxide scale. On the other hand, high energy projection systems used to prepare coatings $\mathrm{S}$ and $\mathrm{T}$ produce a dense and much less porous metallic substrate (porosity of $0.42 \%$ for HVOF and $1.05 \%$ for HFPD as recieved, Table 2), which is not seriously affected by internal oxidation. In this way, there is enough $\mathrm{Al}$ in the metallic particles (which behave as Al reservoir) that, due to density and particle contact in these coatings, can migrate and sustain a protective alumina external layer, with a thickness and continuity similar to those found in blank experiments.

Regardless their similar behaviour against hot corrosion, small differences can be found between HVOF and HFPD coatings. Figure 3. in the Results section shows a higher degree of formation of spinel phase for coating T (T120 line), which is clearly seen in Figure 5, T120 picture, as lighter oxides onto the alumina layer. A detailed characterization of surface composition in Figures 7 and 8 did not give meaningful differences in Al composition; square area EDX composition seemed in turn more useful to find the lineal $\mathrm{Al}$ composition in both coatings. Composition of selected areas present a light $\mathrm{Al}$ reduction in the case of coating $\mathrm{T}$ (picture T120) in respect to coating S (picture S120). The combined effect of spinel formation (risk of spallation and loss of thickness) and Al depletion (intrinsic chemical failure) in coating $\mathrm{S}$ could indicate a higher risk of service damage than for coating $\mathrm{T}$. These findings point out the importance of hot corrosion resistance studies in the comparison of different projection systems, which are commonly performed as a function of composition rather than physical structure.

\section{CONCLUSIONS}

Plasma sprayed NiCrAlY coatings present higher percentage of porosity compared to HVOF and HFPD projection systems for the same composition. This behaviour determines the final performance in hot corrosion experiments with sprayed $\mathrm{Na}_{2} \mathrm{SO}_{4}$ : the fused salt is able to hinder the formation of protective thermally grown surface alumina layer, and $\mathrm{Al}$ is heavily consumed in interparticle oxidation. This $\mathrm{Al}$ depletion in turn involves intrinsic chemical failure and surface layer is comprised by a porous spinel of mixed oxides. On the contrary, high energy projection systems produce dense coatings that, on one hand, suffer a less extent of internal oxidation with less Al consumption and on the other hand, allow the Al migration to external alumina layer. Moreover, this work has pointed out the different behaviour of HFPD and HVOF coatings to hot corrosion, aided with square area EDX analysis of composition and XRD: high velocity oxyfuel is the procedure which gives the lower porosity, rendering a more protective coating against accelerated oxidation in hot corrosion in the conditions studied. 


\section{Acknowledgements}

The authors want to express their gratitude to the Spanish Ministry of Education and Science for the financial support of the work, project MAT2004-02921, and to the Diputación General de Aragón, for the project PM0252004

\section{REFERENCES}

[1] N.M. Yanar, G. Kim, S. Hamano, F.S. Pettit, G.H. Meier Materials at high temperatures 20(4) (2003) 495-506.

[2] A.G. Evans, D.R. Mumm, J.W. Hutchinson, G.H. Meier, F.S. Pettit Progress in Materials Science 46 (2001) 505-553.

[3] H. Guo, H. Xu, S. Gong

Journal of materials science 37(2002) 5333-5337.

[4] D.F. Susan, A.R. Marder

Oxidation of metals, 57(1/2) (2002) 131-156

[5] M. Karadge, X. Zhao, M. Preuss, P. Xiao

Scripta Materialia 54 (2006) 639-644.

[6]H. Echsler V. Shemet, M. Schutze, L. Singheiser, W.J. Quadakkers Journal of Materials Science 41 (2006) 1047-1058.

[7] A. El-Turki, G.C. Allen, C.M. Younes J.C.C. Day

Materials and Corrosion 55 (1) (2004) 24-29.

[8] C. Zhou, J. Yu, S. Gong, H Xu

Surface and Coatings Technology 161 (2002) 86-91.

[9] I.T. Spitsberg, D.R. Mumm, A.G. Evans

Materials Science and Engineering A 394 (2005) 176-191.

[10] C.R.C. Lima, J.M. Guliemany

Surface \& Coatings Technology 201 (2007) 469-4701.

[11] F. Tang, L. Ajdelsztajn, G.E. Kim, V. Provenzano, J.M. Schoenung Materials Science and Engineering A 425 (2006) 94-106.

[12] M. Shibata, S. Kuroda, H. Murama , M. Ode, M. Watanabe, Y. Sakamoto Materials transactions 47(7) (2006) 1683-1642.

[13]A. Scrivani, U. Bardi, L. Carrafiello, A. Lavacchi, F. Niccolai.

Journal of thermal spray technology 12(4) (2003) 504-507

[14] S. Nuutinen, P. Vouristo, S. Ahmaniemi, T. Mantyla, J. Takeuchi.

Proceedings of the International Thermal Spray Conference, Singapore, 2001, 661-670

[15] I. Fagoaga, G. Barykinn, J. De Juan, T Soroa, C. Vaquero. 
Proceedings of the United Thermal Spray Conference, Düsseldorf, Germany, DVS-Verlag, 1999, p 282.

[16] V. Higuera Hidalgo, F.J. Belzunce Varela, J. Riba López

Surface Engineering 22(4) (2006) 277-282

[17]F.J. Belzunce, V. Higuera, S. Poveda

Materials Science and Engineering A297 (2001) 162-167

[18] V. Higuera Hidalgo, F.J. Belzunce Varela, A. Carriles Menéndes, S. Poveda Martínez

Surface Engineering 17(6) (2001) 512-517

[19] V. Higuera, F.J. Belzunce, A. Carriles, S. Poveda

Journal of Material Science, 37 (2002) 649-654

[20] J.A. Goebel, F.S. Pettit, G.W. Goward. Metallic Trasactions 4 (1973) 261.

[21] C.J. Wang, J.S. Ling

Materials Chemistry and Physics 76 (2002) 123-129

[22] W.H. Lee, R.Y. Lin

Materials Chemistry and Physics 77 (2002) 86-96

[23] X. Ren, F. Wang, X. Wang

Surface and coatings Technology 198 (2005) 425-431

[24] R. Mobarra, A.H. Jarafi, M. Karaminezhaad

Surface and coatings technoloby 201(2006) 2202-2007

[25] Q.M. Wang, Y.N. Wu, P.L. Ke, H.T. Cao, J. Gong, C. Sun, L.S. Wen

Surface and Coatings Technology 186 (2004) 389-397

[26] Zhao L., Lugscheider E.

Surface and coatings technology 162(2002) 6-10

[27] Pahalavanyali S., Sabour A., Hirbod

Materials and corrosion 54(9) (2003), 687-693

[28] Sidhu T.S., Agrawal R.D., Prakash S.

Surface and coatings technology 198 (2005) 441-446

[29] D.F. Susan, A.R. Marder

Oxidation of Metals 57 (1/2) (2002) 159-180

[30] W.H. Lee, R.Y. Lin

Materials Chemistry and Physiscs, 77 (2002) 86-96 
Table 1. Plasma (APS), High Velocity Oxyfuel (HVOF) and High Frequency Pulse Detonation spraying parameters.

\begin{tabular}{|l|l|l|l|}
\hline Projection system & \multicolumn{1}{|c|}{ Plasma } & \multicolumn{1}{c|}{ HVFO } & HFPD \\
\hline Coating reference & \multicolumn{1}{|c|}{$\mathrm{R}$} & $\mathrm{S}$ & $\mathrm{T}$ \\
\hline Arc power & $500 \mathrm{~A} ; 70 \mathrm{~V}$ & & \\
\hline Frequency & & & $50 \mathrm{~Hz}$ \\
\hline Carrier gas & Argon & Nitrogen & Nitrogen \\
\hline Projection distance, $\mathrm{mm}$ & 125 & 250 & 150 \\
\hline Fuel & & Hydrogen & Propylene \\
\hline Fuel Flow: & & $7171 / \mathrm{min}$ & $471 / \mathrm{min}$ \\
\hline Oxygen flow: & & $1471 / \mathrm{min}$ & $1391 / \mathrm{min}$ \\
\hline Air compressed: & & $4381 / \mathrm{min}$ & \\
\hline
\end{tabular}

Table 2. Coatings microstructural parameters ( \pm Standard deviation).

\begin{tabular}{|l|r|l|l|l|}
\hline COATINGS & $\mathrm{R}$ (Plasma) & $\mathrm{S}$ (HVOF) & $\mathrm{T}$ (HFPD) \\
\hline Microhardness $\left(\mathrm{HV}_{200}\right)$ & $268 \pm 20$ & $476 \pm 19$ & $361 \pm 14.15$ \\
\hline $\begin{array}{l}\text { Porosity } \\
(\% \text { vol. avg. })\end{array}$ & Surface section & $15.3 \pm 7$ & $0.42 \pm 0.4$ & $1.05 \pm 1.34$ \\
\cline { 2 - 5 } $\begin{array}{l}\text { Oxide content } \\
(\% \text { vol. avg. })\end{array}$ & Transverse section & $10.4 \pm 2.9$ & $0.1 \pm 0.2$ & $0.325 \pm 0.49$ \\
\cline { 2 - 5 } & Transverse section & $7.6 \pm 7.7$ & $14.2 \pm 0.6$ & $15.52 \pm 2.21$ \\
\hline
\end{tabular}




\section{Caption of Figures}

Figure 1. Surface morphology in SEM (secondary electrons) of coatings after 120 hours oxidation at $1000^{\circ} \mathrm{C}$. bR120: coating R, bT120: coating $\mathrm{T}$.

Figure 2. Morphology of coatings $\mathrm{R}, \mathrm{S}$ and $\mathrm{T}$ after 20 and 120 hours oxidation at $1000^{\circ} \mathrm{C}$ with the $\mathrm{Na}_{2} \mathrm{SO}_{4}$ film.

Figure 3. X-Ray characterization of coatings $\mathrm{R}, \mathrm{S}$ and $\mathrm{T}$ after 120 hours oxidation at $1000^{\circ} \mathrm{C}$ with and without (b experiments) the $\mathrm{Na}_{2} \mathrm{SO}_{4}$ film.

Figure 4. X-Ray characterization (40-47 $2 \theta$ section) of coatings $\mathrm{R}$ and $\mathrm{S}$ after 120 hours oxidation at $1000^{\circ} \mathrm{C}$ with the $\mathrm{Na}_{2} \mathrm{SO}_{4}$ film.

Figure 5. Cross sections backscattered electrons micrographs of coatings $\mathrm{R}, \mathrm{S}$ and $\mathrm{T}$ after 20 and 120 hours oxidation at $1000^{\circ} \mathrm{C}$ with and without (b experiments) the $\mathrm{Na}_{2} \mathrm{SO}_{4}$ film.

Figure 6. Coating R (plasma) after 120 hours oxidation at $1000^{\circ} \mathrm{C}$ with (R120) and without (bR120) the $\mathrm{Na}_{2} \mathrm{SO}_{4}$ film, and $\mathrm{Al}$ presence in weight percentage for selected spots (Al+Cr+Ni normalised to 100).

Figure 7. Coating S (HVOF) after 120 hours oxidation at $1000^{\circ} \mathrm{C}$ with $(\mathrm{S} 120)$ and without (bS120) the $\mathrm{Na}_{2} \mathrm{SO}_{4}$ film, and $\mathrm{Al}$ presence in weight percentage for selected spots ( $\mathrm{Al}+\mathrm{Cr}+\mathrm{Ni}$ normalised to 100).

Figure 8. Coating T (HFPD) after 120 hours oxidation at $1000^{\circ} \mathrm{C}$ with (T120) and without (bT120) the $\mathrm{Na}_{2} \mathrm{SO}_{4}$ film, and $\mathrm{Al}$ presence in weight percentage for selected spots (Al+Cr+Ni normalised to 100).

Figure 9. Al presence in weight percentage $(\mathrm{Al}+\mathrm{Cr}+\mathrm{Ni}$ normalized to 100$)$ for selected spots and square areas of $25 \mu \mathrm{m}$ over bS120 sample.

Figure 10. Al presence in weight percentage $(\mathrm{Al}+\mathrm{Cr}+\mathrm{Ni}$ normalized to 100$)$ for square areas of $25 \mu \mathrm{m}$ over bS120, S20, S120, bT120, T20 and T120 samples.

Figure 11. X-Ray characterization of projection powders R preoxidised for 20 hours at $1000^{\circ} \mathrm{C}$ (pRpox) and afterwards mixed with $\mathrm{Na}_{2} \mathrm{SO}_{4}$ grains and thermally treated for 2 hours at $1000^{\circ} \mathrm{C}$ (sample RS).

Figure 12. X-Ray characterization of projection powders $\mathrm{T}$ preoxidised for 20 hours at $1000^{\circ} \mathrm{C}$ (pTpox) and afterwards mixed with $\mathrm{Na}_{2} \mathrm{SO}_{4}$ grains and thermally treated for 2 hours at $1000^{\circ} \mathrm{C}$ (sample TS). 
ACCEPTED MANUSCRIPT
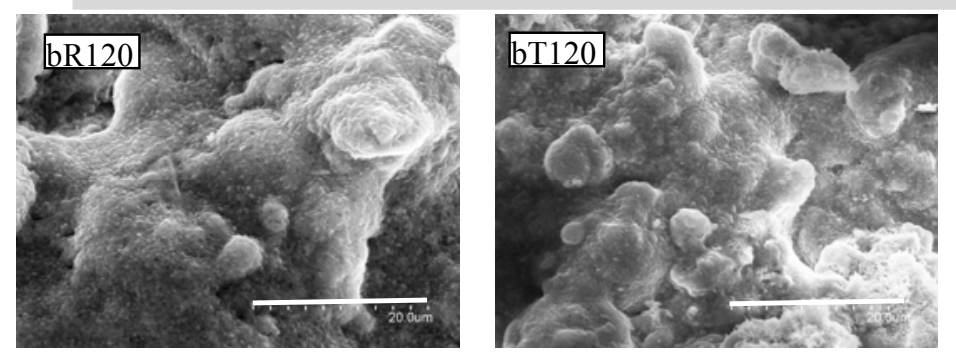

Figure 1

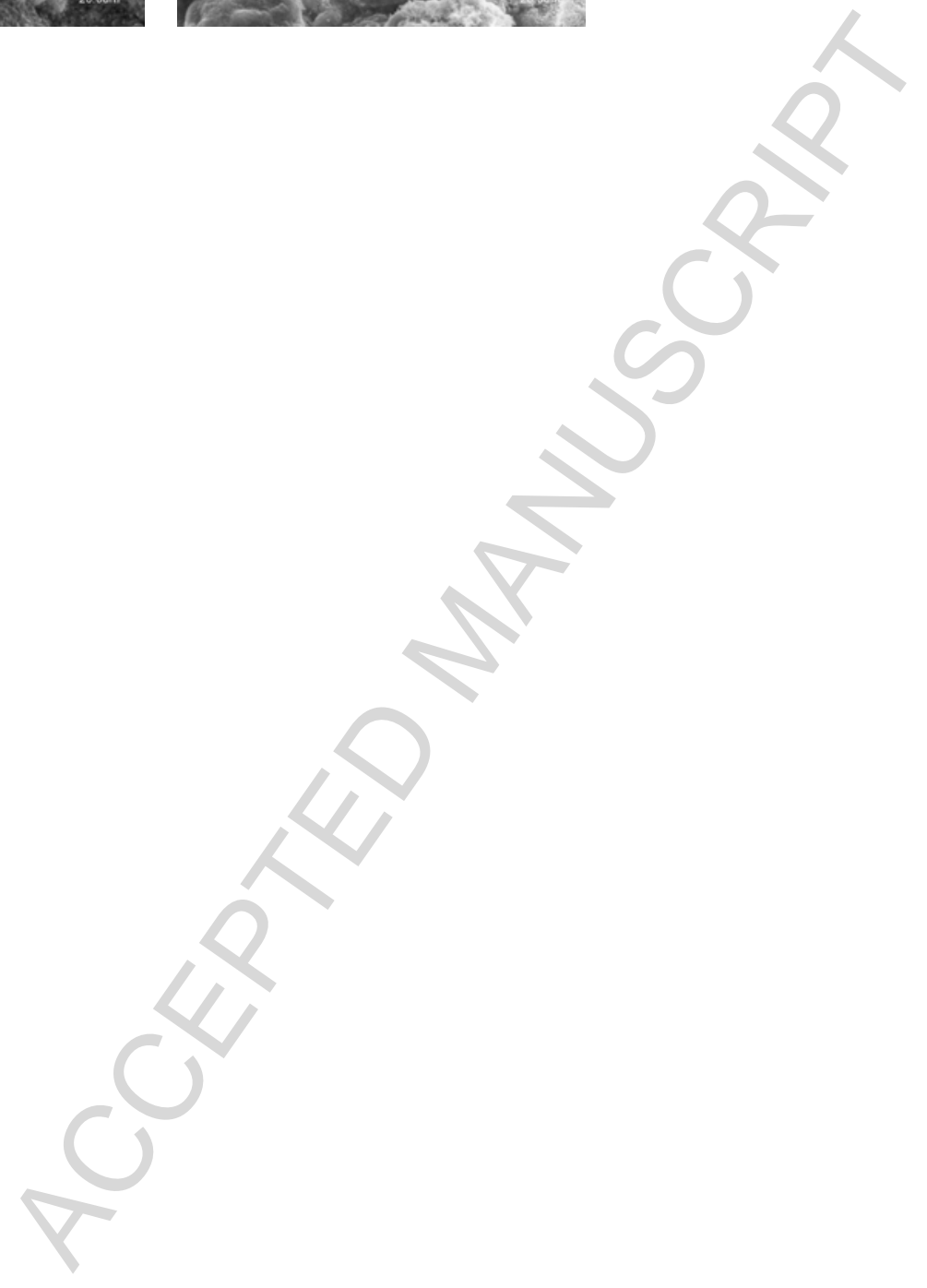



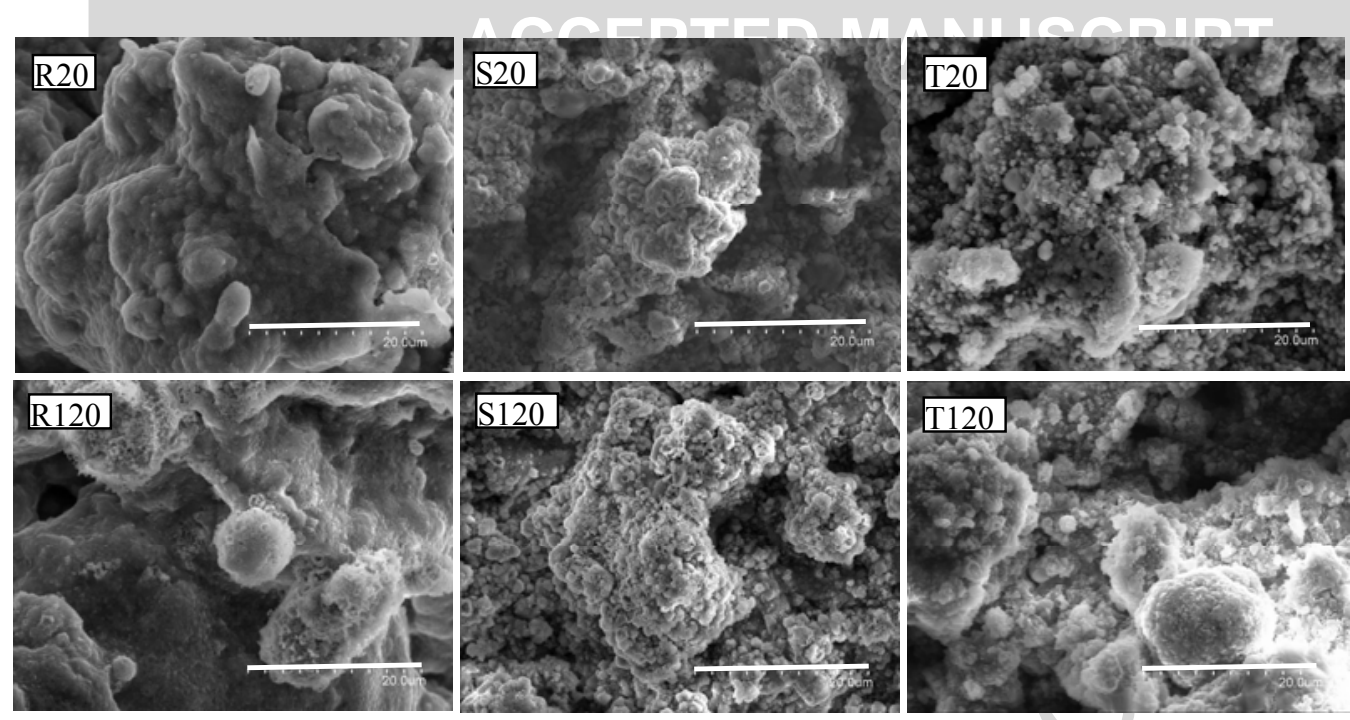

Figure 2 


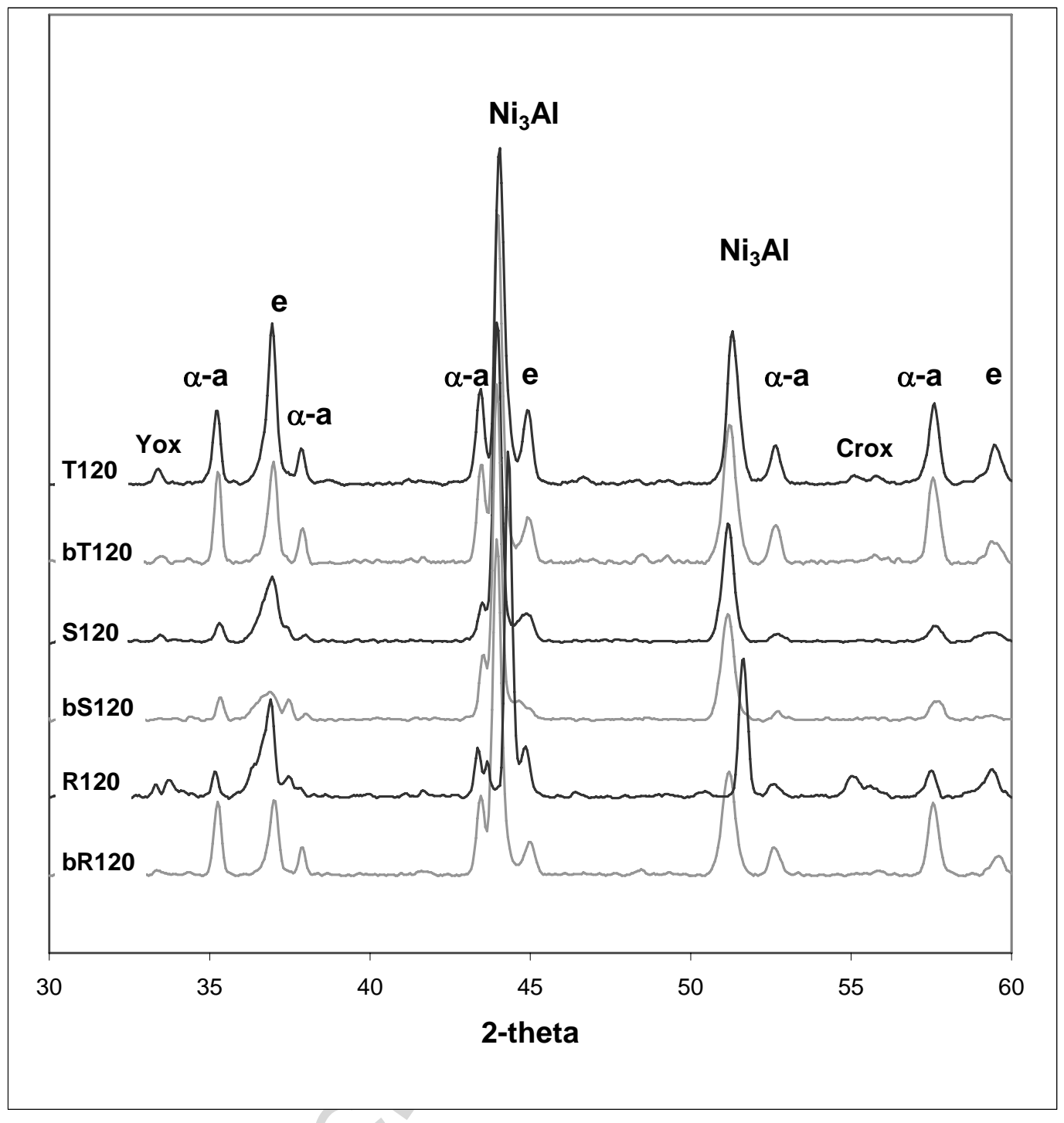

Figure 3 


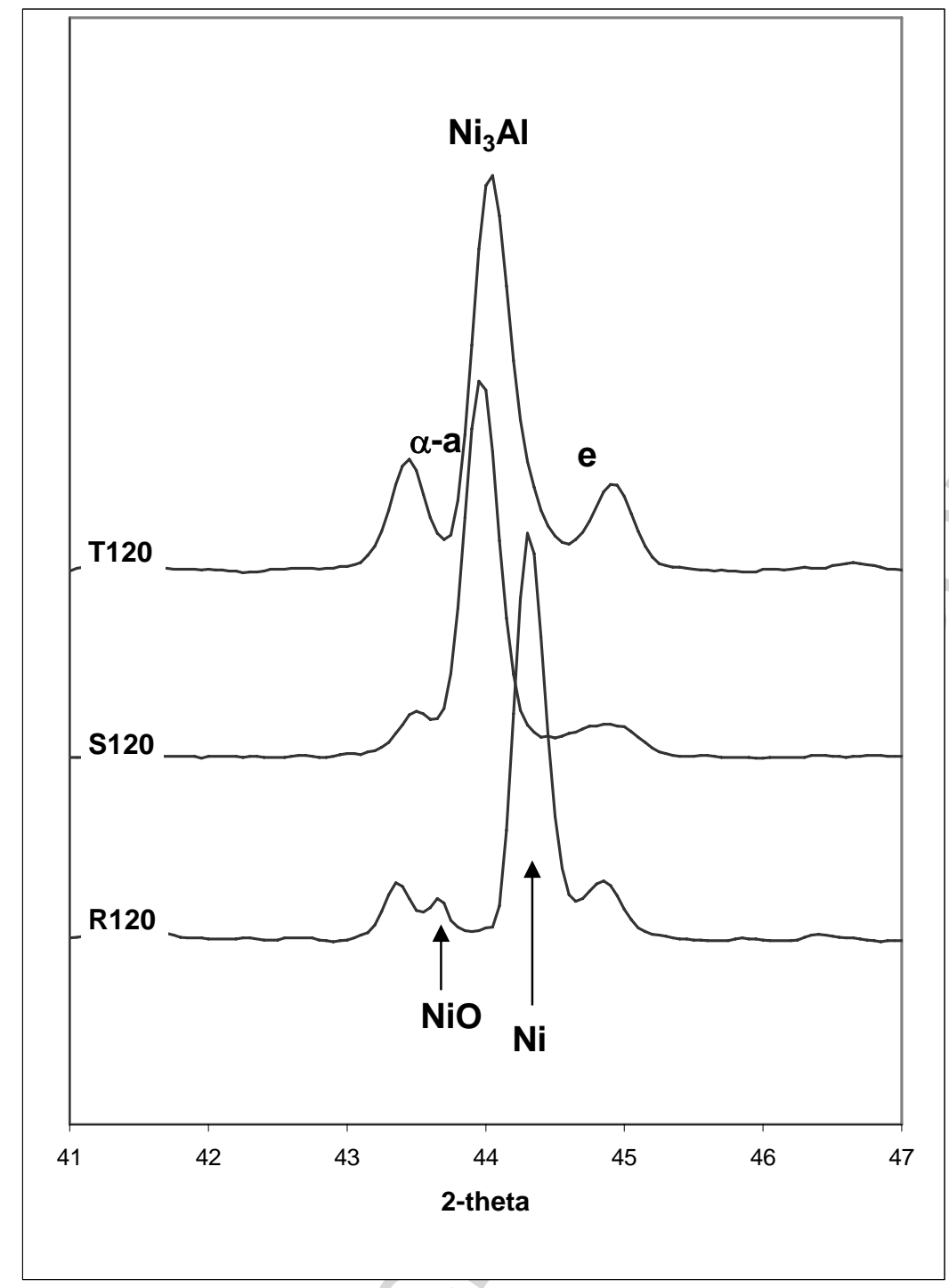

Figure 4 


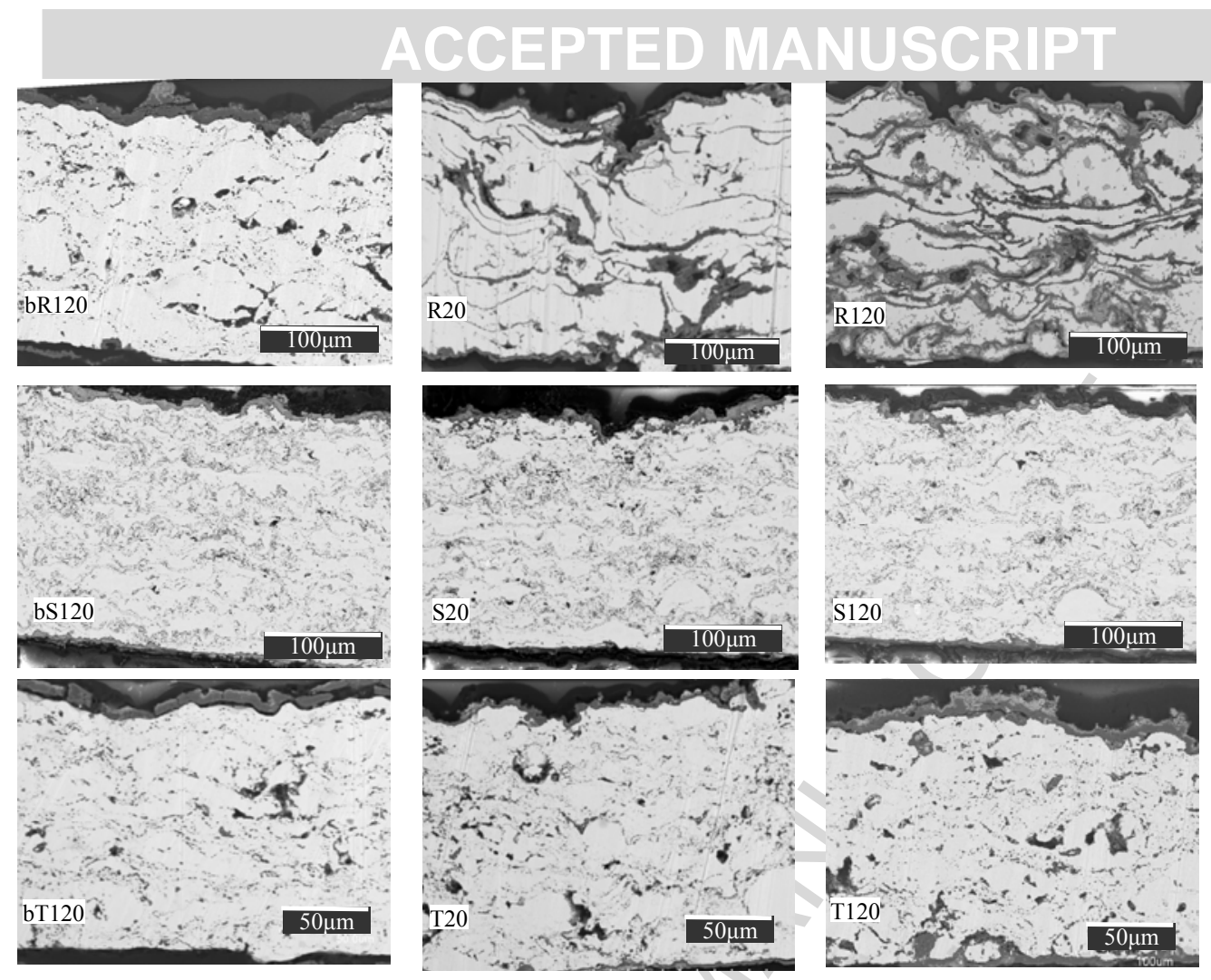

Figure 5 


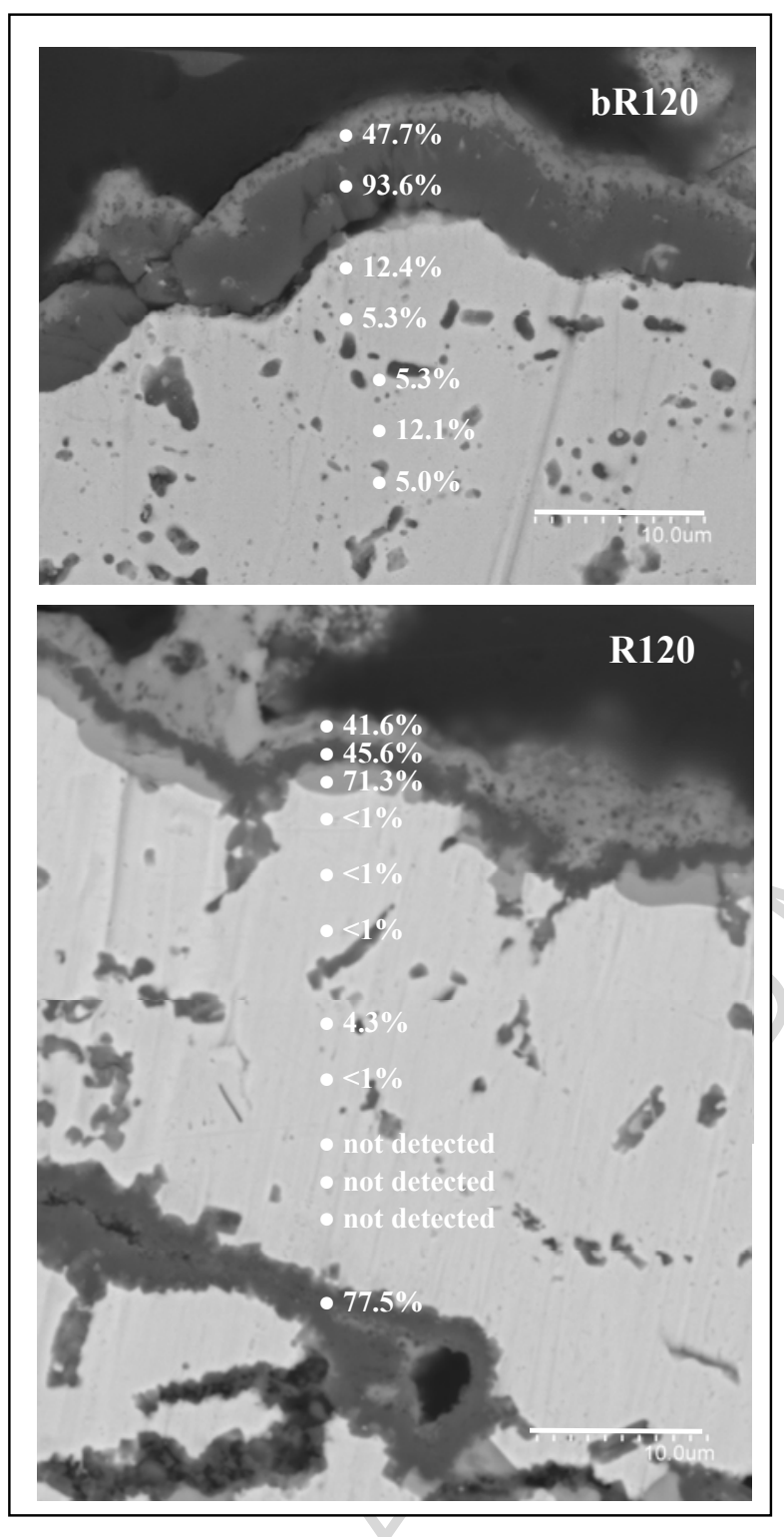

Figure 6 


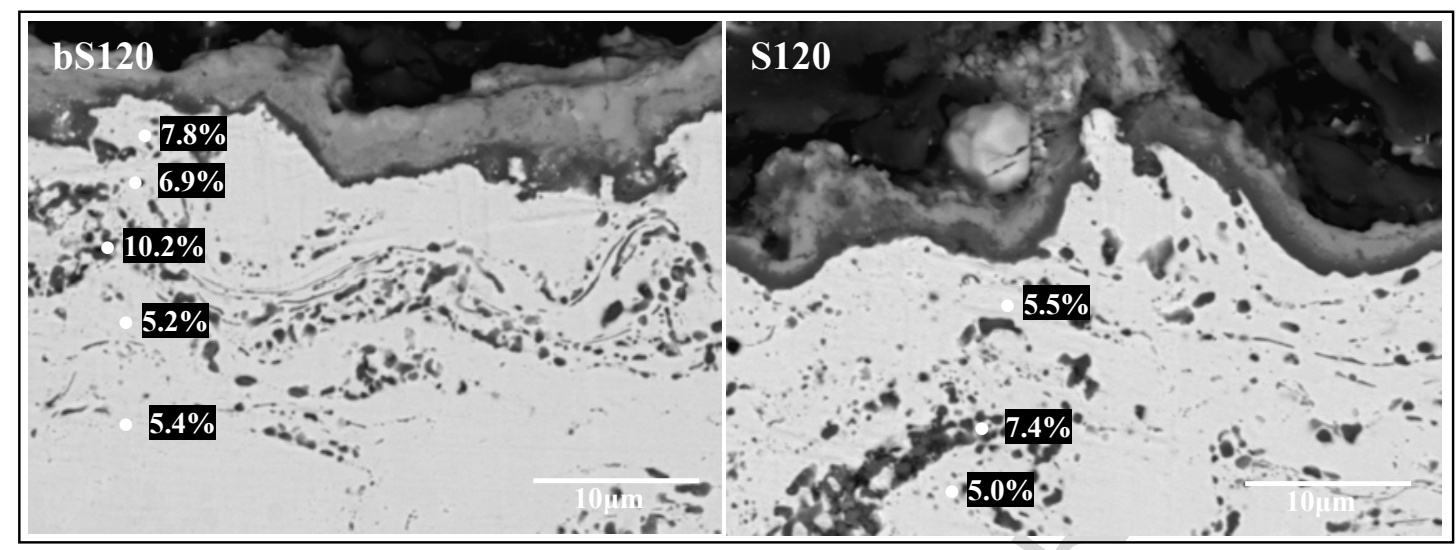

Figure 7. 


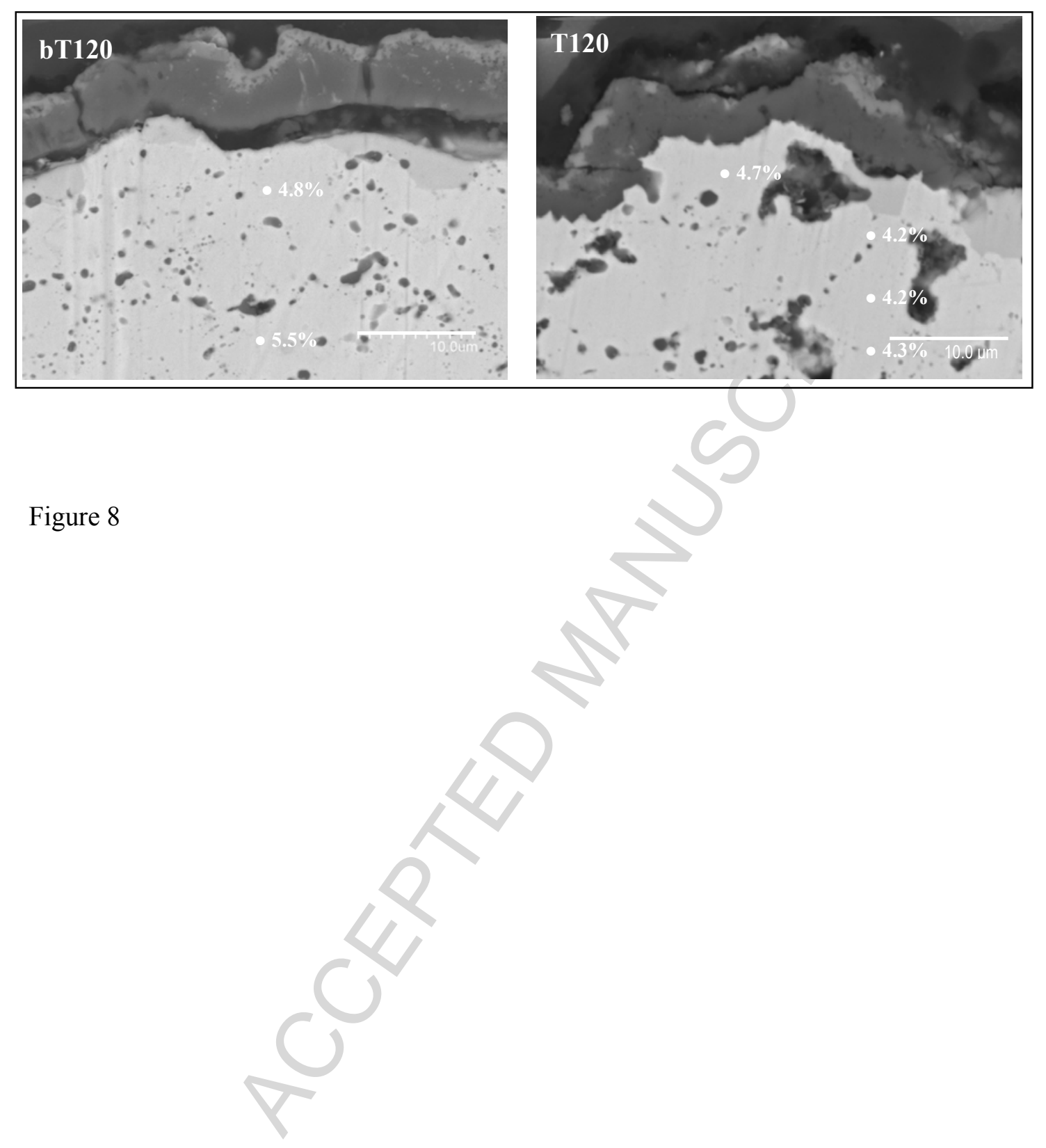


Figure 9

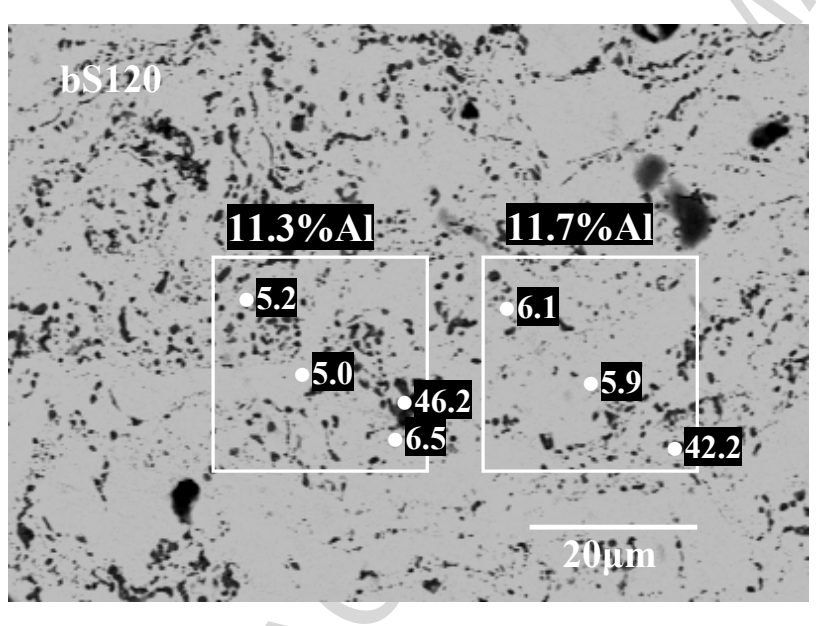




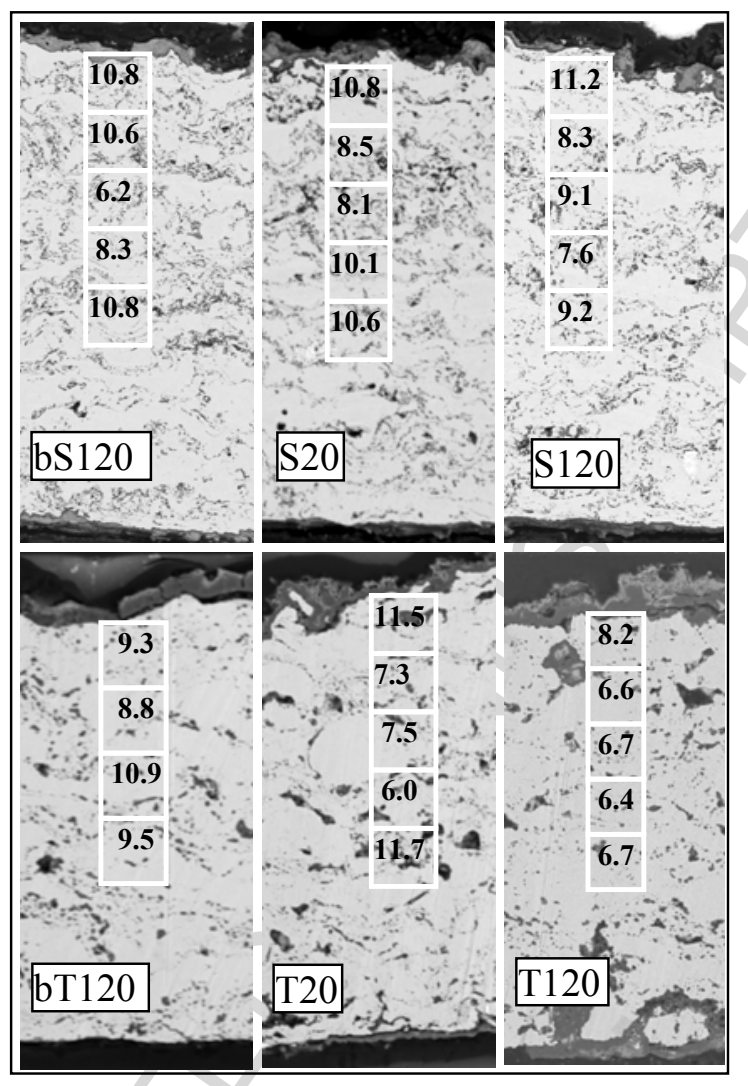

Figure 10. 
Figure 11.

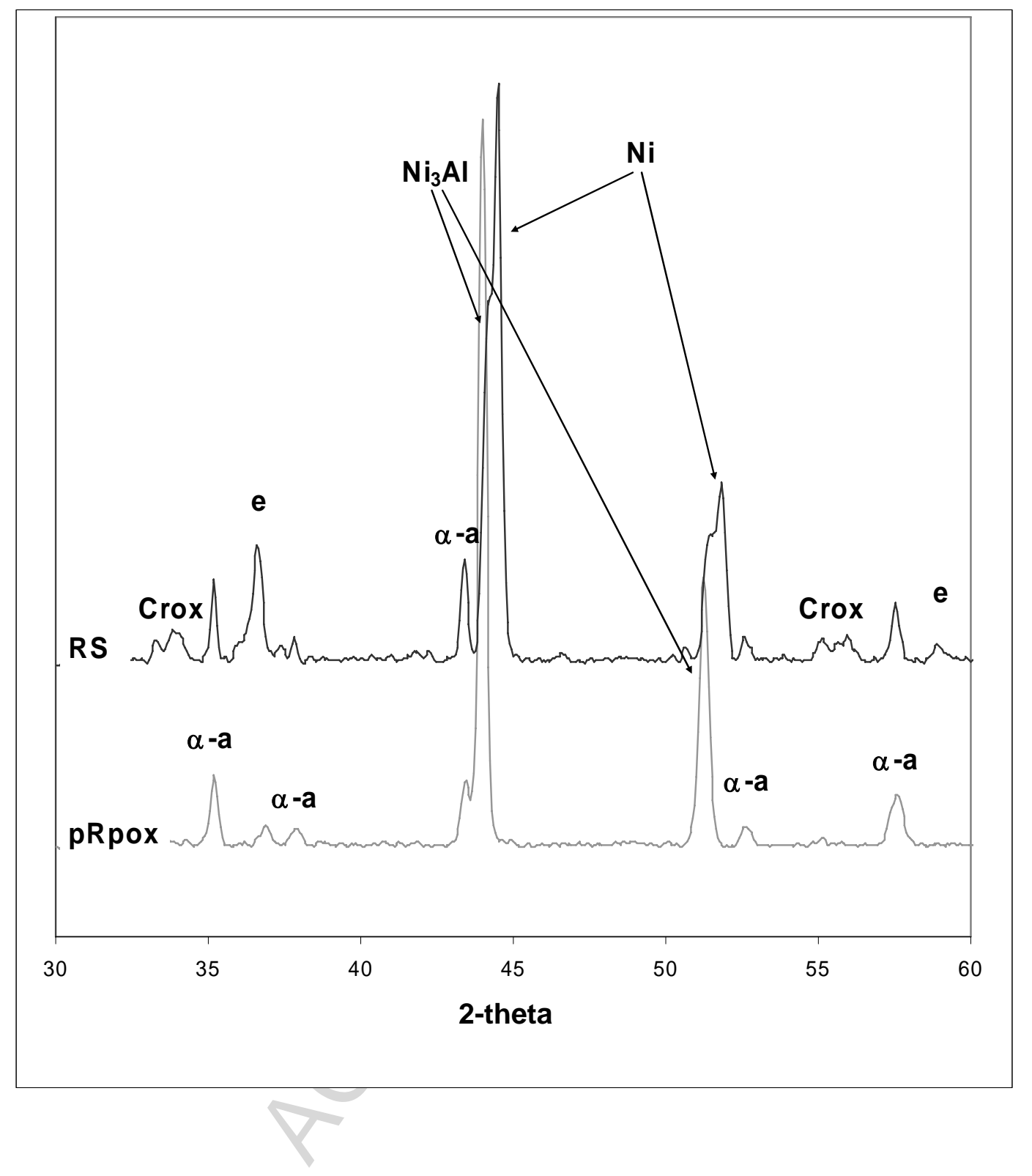


ACCEPTED MANUSCRIPT

Figure 12

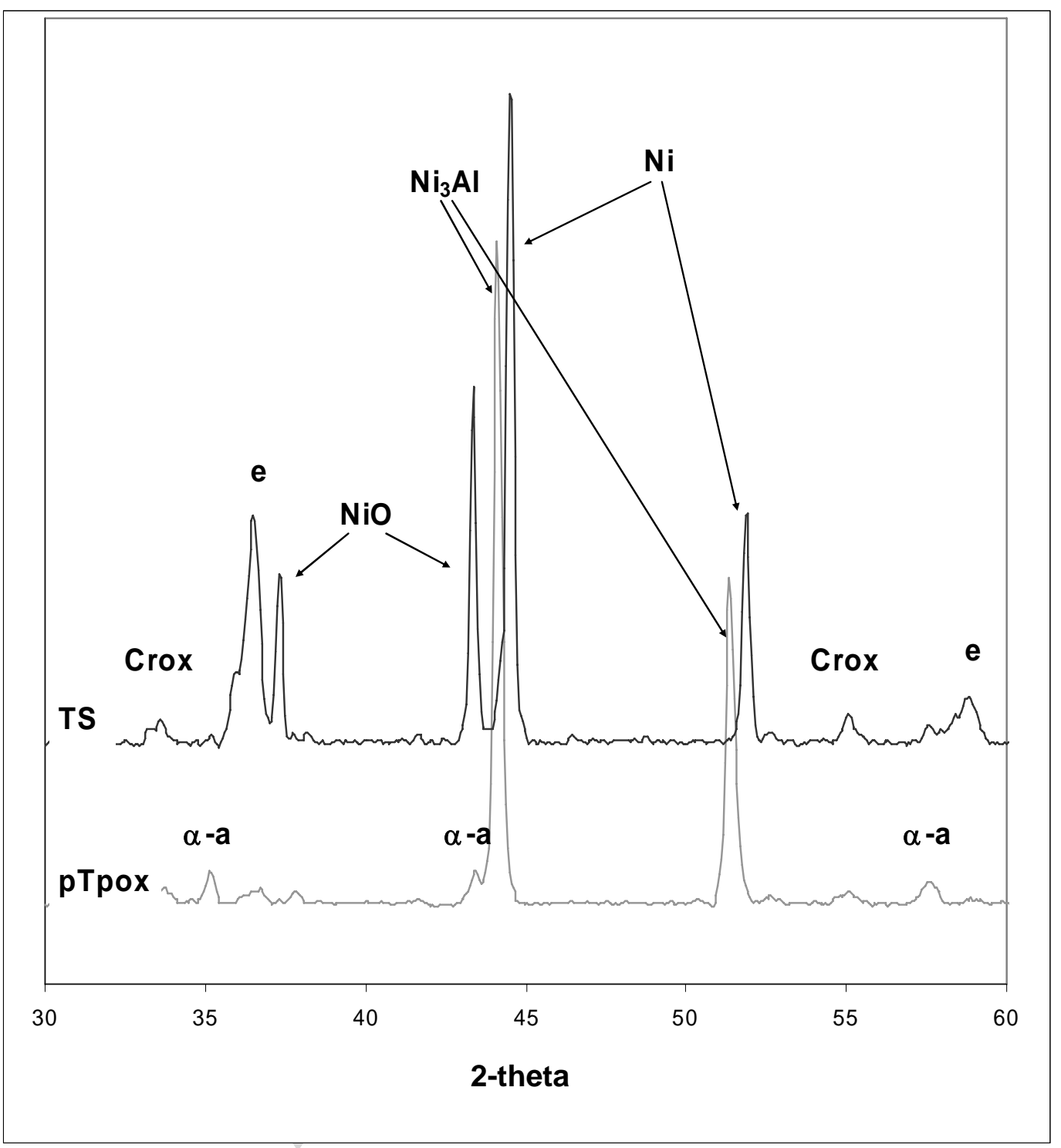

